\title{
Power Relations of Negotiation
}

\section{Coordination}

Being part of a collaboration requires participants, both historians and computational experts, to negotiate the goals of the collaboration and the individual tasks of participants. This process is called coordination, defined as "the integration or linking together of different pieces of a project to accomplish a collective task." ${ }^{363}$ Coordination is a continuous process, enduring as long as the collaboration does. Throughout the collaboration, participants are in constant negotiation of the project goal(s), while mutually accountable towards one another to fulfil their individual tasks. In the framework of communities of practice, this is the second dimension: the joint enterprise. Through the process of negotiation of a common goal, the pursuit of that common goal and the mutual accountability towards one another in that pursuit, the joint enterprise is what keeps the collaboration together. ${ }^{364}$

Yet a collaboration does not exist in a vacuum, as the previous chapter showed. Negotiations are positioned in a broader system that influences the collaboration, such as the institutes where collaborators are employed, their disciplinary backgrounds, funding structures etc. Furthermore, negotiations are not necessarily level, although this would be the preferred situation, but can be conducted through different power relations. In his exploration of the trading zones of physics, the historian of science Peter Galison discussed three metaphors employed by physicists who feared a loss of control. ${ }^{365}$ First, the metaphor of prostitution was used to critique physicists selling out to engineering, focusing on applied rather than fundamental research. Second, the metaphor of handmaidens described the relationship between a boss and a servant, with physicists demanding engineers to perform certain tasks. Third, the metaphor of flies and spiders was used to warn of the danger of physicists following engineers for too long, after which they end up trapped and unable to return.

Control, and specifically who is in control, is an aspect of great significance to the participants of trading zones, leading to desirable or less desirable outcomes. These interactions between participants in trading zones, through coordination and control, are the focus of the current chapter. This chapter thereby

363 Cummings and Kiesler, "Collaborative Research Across Disciplinary and Organizational Boundaries," 704.

364 Wenger, Communities of Practice, 77-78.

365 Galison, Image and Logic, 249, 255, 277-78.

Ә Open Access. (C) 2021 Max Kemman, published by De Gruyter. (c) BY-NC-ND This work is licensed under the Creative Commons Attribution-NonCommercial-NoDerivatives 4.0 International License.

https://doi.org/10.1515/9783110682106-004 
explores the second dimension of trading zones, namely the power relations between (groups of) people.

\section{Studying Power Relations through the Coordination of Individual Incentives}

In order to investigate power relations in coordination, I take a bottom-up approach on a micro scale, starting from what drives individual participants' practices in the collaboration. From this bottom-up approach, I consider where participants explicitly or implicitly agree or disagree. To understand how participants negotiate their own practices, goals and tasks and those of others, I investigate their incentives. ${ }^{366}$ The goals and incentives of participants in collaborations are not necessarily homogeneous, and the goal of the collaboration as a whole does not necessarily match the individual goals of participants. ${ }^{367}$

In her study of a collaboration between earth scientists and computer scientists, the information scientist Judith Weedman found that the individual incentives of participants significantly impacted the coordination of the collaboration. ${ }^{368}$ In this collaboration, she problematised the negotiations required for all participants to agree when the digital system under development was finished. As participants had different incentives, they had different points at which they considered the system to be finished. Depending on one's incentives, a participant may even argue a system is never truly finished. ${ }^{369}$ Thus, to better understand these discrepancies and the required coordination, she investigated the individual incentives of participants according to three aspects: 1 ) reasons for joining the project, 2) individual goals for the project and 3) expected effects of participation after the project has ended. As a short-hand, I refer to these aspects as 1) reasons, 2) goals and 3) expectations.

These three aspects of incentives provide insights at different points of coordination. Reasons show the ambitions of participants before or at the start of the collaboration, before coordination determines what may be feasible or not. Goals may be continuations of the reasons for joining, as participants stick to their

366 Judith Weedman, "The Structure of Incentive: Design and Client Roles in ApplicationOriented Research,” Science, Technology \& Human Values 23, no. 3 (1998): 315-45, https://doi. org/10.1177/016224399802300303.

367 Karin Knorr Cetina, The Manufacture of Knowledge: An Essay on the Constructivist and Contextual Nature of Science (Pergamon Press, 1981), 43.

368 Weedman, "The Structure of Incentive."

369 Susan Brown et al., "Published Yet Never Done: The Tension Between Projection and Completion in Digital Humanities Research," Digital Humanities Quarterly 3, no. 2 (2009). 
original incentives. Yet through coordination and experiences in the collaboration, additional goals may be added, ambitions might be discarded, or ideas become clearer in the discussion of current practices. Expectations represent not so much what participants desire to achieve during a collaboration, but what participants expect to gain from a participation. Beyond the outcomes of a project, expectations may refer to expected shifts in practices following the sharing of practices in a collaboration. These expectations can thus be continuations of the individual goals or can be alternative paths when individual goals did not come to fruition, or additional expectations added due to positive results. By combining these three aspects, I aim to uncover incentives that stick during the duration of a collaboration, and are thus successfully preserved in negotiations, or incentives that change over time, and are thus shaped by negotiation.

Yet to understand how individual incentives are negotiated, it is necessary to consider pre-existing power mechanisms that render one participant's incentives more likely to survive than another's. I identify two such power mechanisms that position each participant in a specific role in digital history collaborations. First, as part of the hierarchical structure of academia, participants have a position as $\mathrm{PhD}$ candidate, postdoc, professor, or otherwise. A participant in the role of professor is in a more powerful position than a participant in the role of $\mathrm{PhD}$ candidate or postdoc. As I found in the previous chapter, historians outnumbered computational experts as participants as well as in positions of leadership of collaborations. This imbalance suggests a power relation. Yet historians as envisioned end-users are dependent on computational experts as system designers. In their "ability to implement technological change”, computational experts are in a more powerful position than historians who are dependent on this technological change. ${ }^{370}$ The second power relation of interest then is disciplinary expertise, which may lead to pushing of technology or a pulling of technology services.

This is not to say that these are the only power relations imaginable. It is impossible to consider all the power mechanisms in a trading zone, for there are far too many. ${ }^{371}$ The above two mechanisms, academic position and disciplinary expertise, leave out aspects such as gender, ethnicity, socio-economic status, or the status of institutes or disciplinary communities. ${ }^{372}$ Such mechanisms of power

370 M. Lynne Markus and Niels Bjorn-Andersen, "Power Over Users: Its Exercise By System Professionals," Communications of the ACM 30, no. 6 (1987): 503.

371 Hayward, De-Facing Power.

372 For more elaborate discussions of intersectionality in digital humanities, see Roopika Risam, "Beyond the Margins: Intersectionality and the Digital Humanities," Digital Humanities Quarterly 9, no. 2 (2015); Barbara Bordalejo and Roopika Risam, Intersectionality in Digital Humanities (Arc Humanities Press, 2019). 
are important and deserving of study. However, such power mechanisms are not necessarily specific to digital history collaborations as trading zones. Without ignoring these matters then, they fall outside the scope of my analysis. Participants are instead contextualised by their academic position and disciplinary background.

\section{Interviews}

To study power relations in trading zones I interviewed participants from a number of case studies, described in the next paragraph. For these case studies, I interviewed as many participants as feasible, to gain insight in the different individual perspectives and incentives for participation in a collaboration. Where possible, interviews were conducted face-to-face by visiting a site and interviewing all present participants. Additional interviews were conducted at later times via Skype. This furthermore provided me insights at different time frames, both during coordination as well as reflections afterwards. I ultimately conducted 28 interviews with 24 participants.

As such, the below analysis considers power relations in reflections and individual incentives, rather than in practice such as may be observed during meetings. In cases where I noticed present disagreements during a visit, I tried to cover this in the interviews. Rather than an ethnographic participant observation, this chapter thereby follows an approach of critical discourse analysis of how collaborators discuss their ambitions, expectations, goals, and frustrations, in order to uncover the power relations underlying these discursive practices. ${ }^{373}$

The majority of interviewees had a background in history, in line with the finding of the previous chapter that digital history collaborations predominantly consist of historians. The incentives uncovered in the interviews might consequently mainly reflect the incentives of historians and should not be seen as an exhaustive list for all collaborators. The uncovered incentives are as such not necessarily generalisable to all digital history collaborations. Instead, my goal is to investigate the negotiation of incentives and tasks, rendering visible the practices of boundary crossing and construction that are arguably generalisable.

Seventeen participants were male and seven were female, where male and female interviewees were distributed over the different positions and disciplinary backgrounds. Four interviewees had the position of "coordinator", an unconventional position in academia. The tasks of a coordinator usually consisted of,

373 Michel Foucault, The History of Sexuality Volume I: An Introduction, trans. Robert Hurley (Pantheon Books, 1978); Gilbert Weiss and Ruth Wodak, eds., Critical Discourse Analysis (London: Palgrave Macmillan UK, 2003), https://doi.org/10.1057/9780230288423. 
among other things, bringing collaborators together, communicating between parties, keeping track of practical matters and reporting to the PI of the collaboration. Noteworthy is that three of the four coordinators did not have a $\mathrm{PhD}$ title, introducing a possible power relation according to academic hierarchy, to which I return below. For an overview of interviewees see Table 2. All interviews were recorded and manually transcribed and coded in MAXQDA. Coded segments were printed out and manually grouped together to find statements referring to similar concerns. Below I analyse these different concerns and present quotes as examples. Some quotes have been edited slightly for readability. More importantly, the below quotes are translations of statements, since most of the interviews were conducted in Dutch. The quotes included in the analysis below are not thus exact replications of utterances by interviewees.

As can be seen in Table 2, the majority of the interviews was conducted in late 2015. During this first round of interviews, I uncovered rich points deemed of interest for further investigation in later interviews. ${ }^{374}$ Furthermore, interviews were conducted through co-construction. Interviewees could fully speak their minds, not only in answering questions but also reflecting on the validity of questions or the need for additional questions. ${ }^{375}$ Interviewees could moreover suggest

Table 2: Overview of interviewees by disciplinary background, their position in the collaboration, gender and the period in which interviews took place.

\begin{tabular}{lrlrlrlrr}
\hline DISCIPLINE & $\#$ & $\begin{array}{l}\text { ACADEMIC } \\
\text { POSITION }\end{array}$ & $\#$ & GENDER & \# & $\begin{array}{l}\text { PERIOD OF } \\
\text { INTERVIEW }\end{array}$ & $\#$ \\
\hline History & 15 & Professor & 8 & Male & 17 & Late 2015 & 16 \\
\hline $\begin{array}{l}\text { Computational } \\
\text { research }\end{array}$ & 4 & Postdoc & 5 & Female & 7 & Late 2016 & 1 \\
\hline $\begin{array}{l}\text { Software } \\
\text { development }\end{array}$ & 3 & PhD & 4 & & & Early 2017 & 4 \\
\hline \begin{tabular}{l} 
Other humanities \\
\hline Library
\end{tabular} & 1 & Coordinator & 4 & & & Early 2018 & 3 \\
\hline TOTAL & 1 & Software & 3 & & & Mid 2018 & 4 \\
\hline
\end{tabular}

374 Agar, "Ethnography."

375 Barbara Sherman Heyl, "Ethnographic Interviewing," in Handbook of Ethnography, ed. Paul Atkinson et al. (SAGE Publications, 2001), 369-83. 
who else to interview. Based on this feedback, I interviewed several scholars outside of the four case studies.

A significant concern developed through co-construction was the balance between contextualisation and confidentiality. When an analysis explicitly mentions which people were interviewed from which collaborations and quotes interviewees by name this gives advantages both in understanding the particularity of case studies and fully exploring the consequences of problems. However, as interviews included disagreements between collaborators, several interviewees preferred to remain anonymous. Therefore, this chapter takes a number of precautions that aim to maximise the analysis of power relations, also in exploring collaboration failures and disagreements, while minimising the identifiable information of interviewees. To contextualise statements of interviewees as part of power mechanisms, I include per statement the academic position of the interviewee and their disciplinary background. All quotes are numbered so that I can refer back to quotes.

Per case study I mention the number of interviewees, the disciplinary backgrounds and positions of interviewees, but not in combination. To anonymise statements, I have furthermore decided to omit several aspects of interviewees. In order not to provide too much information that renders interviewees identifiable, I do not distinguish between different professorships (assistant, associate, or full), but refer to all these interviewees as "professor". I also refer to all interviewees as female, rather than reveal the gender of interviewees. ${ }^{376}$ I take this same approach to my description of the case studies in the following section, where I give an abstract description of their goals without rendering them (easily) identifiable. As a result of this approach, rather than exploring power relations per case study, I generalise my discussion of power relations as they relate to digital history trading zones, without explicitly referring to case studies.

This chapter thereby takes a different approach than the previous chapter. The previous chapter was rooted in oral historical and ethnographic research, exploring the contingencies and particularities of emerging trading zones that were, therefore, identifiable. In contrast, this chapter takes inspiration from social scientific research, exploring aspects of trading zones that may be of significance beyond the particular case study. ${ }^{377}$

376 The practice of referring to all interviewees as female is inspired by Thomas Franssen et al., "The Drawbacks of Project Funding for Epistemic Innovation: Comparing Institutional Affordances and Constraints of Different Types of Research Funding," Minerva 56, no. 1 (March 2018): 11-33, https://doi.org/10.1007/s11024-017-9338-9.

377 Desirée Ciambrone, “Anonymity," in The SAGE Encyclopedia of Social Science Research Methods, ed. Michael Lewis-Beck, Alan Bryman and Tim Futing Liao (Sage Publications, Inc., 2004), 18-19, https://doi.org/10.4135/9781412950589.n17; Heather L. Ondercin, "External Validity," in The 


\section{Case Studies}

After a review of digital history collaborations in Belgium, the Netherlands and Luxembourg, I chose four collaborations as case studies; two from Belgium and two from the Netherlands. I chose collaborations that included both historians and computational experts and that were still ongoing. In order to contextualise the interviews, in this section I provide a brief description of the case studies and what each collaboration aimed to achieve. These descriptions are based on the interviews as well as on document analysis of proposals and publications.

\section{Case Study 1: Development of a Large-scale Unstructured Database}

The first case study was a four-year project with scholars from multiple universities, where most of the scholars were from history. One research group had digitised material available which laid the basis for the project. Additional data was to be collected and digitised in collaboration with a cultural heritage institute. The project envisioned the development of a system that would combine databases for a bibliography, for unstructured textual data and for structured data (people, places and relations between entities as extracted from the unstructured data). These databases were to be integrated so that historians could jump from structured to unstructured data to find all occurrences of an entity in the texts, or vice versa from the text to find more information about an entity. For example, historians would be able to select a historical person and where this person is mentioned in other texts, as well as gain an overview of related historical persons. The extraction of these entities from the unstructured data was part of the tasks of the computational experts.

The structured database used an existing platform, with some modifications on the level of user interactions and data export. The project hired the developers of the platform to make these modifications. The unstructured database in contrast was built from scratch. A commercial software development company was hired to set up the system and develop required features. Both the developers of the structured database and the developers for the unstructured database were

SAGE Encyclopedia of Social Science Research Methods, ed. Michael Lewis-Beck, Alan Bryman and Tim Futing Liao (Sage Publications, Inc., 2004), 360-62, https://doi.org/10.4135/9781412950589. n318; Peggy Wallace, “Anonymity and Confidentiality," in Encyclopedia of Case Study Research, ed. Albert Mills, Gabrielle Durepos and Elden Wiebe (SAGE Publications, Inc., 2010), 22-24, https://doi. org/10.4135/9781412957397.n9. 
based in different countries than the historians, so that the technical work was conducted on a large physical distance.

The project included several $\mathrm{PhD}$ candidates in history, who were envisioned to use the integrated system for their research. However, while the structured database was successfully implemented and used, the unstructured database posed many challenges and delays. Digitisation of the collections took much longer than anticipated. The digital platform never reached a level of usability where it could facilitate research. Due to these problems, the unstructured database never came to fruition, nor were the databases ultimately integrated in a single system. PhD candidates consequently started entering unstructured data into the structured database instead. This led to questions of whether the structured database needed to be customised to better facilitate unstructured data or whether to continue investments in the envisioned unstructured database. The delay in the unstructured data platform proved especially problematic for the $\mathrm{PhD}$ candidates from computational research, who had to resolve to other datasets for their research on unstructured data. The ambition that the work of the PhDs candidates in computational sciences could support the work of the $\mathrm{PhD}$ candidates in history was, therefore, abandoned.

I conducted nine interviews with seven participants of this collaboration, spread out over a period of two and a half years. Of these seven participants, five came from history and two from computational research. Three interviewees were professors supervising the research, three were $\mathrm{PhD}$ candidates and one was a coordinator. I furthermore had informal discussions with the software developers of the structured database.

\section{Case Study 2: Development of a Structured Database Integrating Data from Multiple Cultural Heritage Institutes}

The second case study was a four-year project at a single university. The main collaborators shared an office or had offices in the same hallway, making it a collaboration on a small distance. The collaborators were from different disciplinary backgrounds, about evenly distributed between historians and computational researchers and software developers. Data was collected in collaboration with several cultural heritage institutes. The software developer performed his tasks within the office of the other collaborators. Later in the project this developer was replaced by a software company from another country. During this period the computational researcher on the project spent time at the software company to coordinate development. The collaboration thus emphasised short distances and face-to-face communication throughout the entire project. 
The envisioned system integrated the data from the different cultural heritage institutes in a structured database. Some of these datasets were unstructured data and the task of the computational researcher was to extract the entities and entity descriptions so they could be integrated in the structured data. In the first version, software development consisted of creating several visualisations that showed connections between datasets containing an entity, in a way that historians could analyse this information. This system was later replaced by a search interface where historians could search for entities to find in which databases they occurred. As this was a significant shift, the software developer was replaced. The $\mathrm{PhD}$ candidate in history was envisioned to use the system for their research. Yet although the system was successfully implemented, it was finalised only late in the project so that the $\mathrm{PhD}$ candidate did not end up using the system.

I conducted six interviews with five participants of the collaboration. Three interviewees came from history, one from computational research and one from software development. All interviewees had different roles in the project: one professor supervising the project, one coordinator, one postdoc, one $\mathrm{PhD}$ candidate and one software developer.

\section{Case Study 3: Establishing a Digital Humanities Centre}

The third case study was an alliance of scholars with the aim to promote digital humanities at their university. During my first round of interviews, the so-called centre consisted of three participants who were located in different buildings of the same university.

A point of interest was the diverging ambitions for the centre, which were connected with the individuals' visions of digital humanities as a whole. While one scholar argued that like digital humanities the centre should disappear within a couple of years, the other envisioned a key role in the development of research infrastructures for the humanities at large. The centre later grew substantially, with affiliates at several humanities research groups from the university and a core of project coordinators and software developers that were located close together. The centre had not yet fully stabilised in form and ambition, but was already actively providing a service role, hosting existing tools and developing new ones.

I conducted four interviews with three participants of the collaboration. All three were in senior positions, including two professors and a coordinator. The three interviewees had different backgrounds in history, literature and the library. 


\section{Case Study 4: a Software Team for the Humanities}

The fourth case study was a team working to support humanities scholars in their university. Led by a senior scholar with a background in history, the rest of the team consisted of a postdoc and software developers with backgrounds in computer science, artificial intelligence or computational linguistics. All software developers had some affinity with humanities subjects. The team was located in a single office but collaborated with scholars that could be in any other building of the university. Scholars could apply for programming time with a project proposal describing their research project and the requirements for a digital tool to facilitate this research. Programming time was limited to three months part-time of one developer, for which costs would be covered by the university. For larger research projects, more programming time could be requested but this had to be covered financially by the budget of the requesting project. Different from the other case studies, this collaboration developed a wide range of small tools for very specific and predefined research practices. These tools were made to be generic, so that they could be reapplied to other research projects. When the team thought a certain research practice was already covered by existing tools they referred to these tools and rejected the request.

I conducted three interviews with three participants. ${ }^{378}$ One interviewee was the leading senior scholar and two were developers.

\section{Other Interviews}

To further contextualise the case studies and broaden perspectives, I conducted six additional interviews outside of the case studies where I did not necessarily collect perspectives from multiple participants of a project. From these additional interviewees, five were from history and one from computational research. Three interviewees were professors, and the other three were in postdoc positions or reflected on past participation as a postdoc in a collaboration.

378 I conducted a fourth interview, but the recording failed. I have subsequently excluded this interview from analysis. 


\section{Incentives}

You have a research idea and you fit that to the call to which you apply. If you get a grant, you try to accomplish your research idea as well as possible. And when you hire researchers, they of course have their own idea and their own line of research they want to work on as well, and they try to fit that into the research project.

(coordinator with background in history - Q1)

As the above quote shows, a project is shaped in multiple stages by the different incentives of participants. To understand the coordination of practices as uncovered in the case studies, in this section I detail the identified incentives of participants. Below, I first describe incentives according to the three factors introduced above: 1) reasons for joining, 2) individual goals and 3) expected effects of participation after the collaboration has ended. By describing the incentives bottom-up, I aim to identify communities of participants with shared incentives. In the next section, I investigate how incentives may conflict with one another.

\section{Reasons for Joining}

For the instigators of the collaboration, usually the professor and coordinator, this question is harder to answer. In an online questionnaire on digital humanities collaborations I asked respondents why they had joined their collaboration, to which almost 20\% responded that they were the principal investigator (PI). ${ }^{379}$ Since they did not join the collaboration, but conceived it, PIs tend to return to the goals as described in the grant proposal as their reason for joining or starting the collaboration. Nevertheless, for both PIs and for researchers employed after a grant, a number of reasons to join can be distilled from the interviews.

One reason, also present in quote Q1, was to acquire funding for research. For example, in one case study, a research group joined the collaboration for the following reasons:

One reason we joined was to acquire funding for a $\mathrm{PhD}$. Another reason was to implement our already existing research in a larger context, and thereby to jointly collect more data.

(professor in history - Q2)

Not only did this research group join to advance existing research, they looked for additional funding to do so. This reason was mainly shared among the professors and coordinators as collaboration instigators. As many incentives were

379 Kemman, "Boundary Practices of Digital Humanities Collaborations.” 
shared by participants in these two roles, in the rest of this section I refer to them in combination as instigators.

Another reason that is equally pragmatic was to acquire a research position. This reason was especially common among the participants in $\mathrm{PhD}$ and postdoc positions. What is of interest is that several interviewees joined a digital history collaboration without necessarily doing so due to an intrinsic interest in digital history. For example, one historian said that "when I applied, I knew little or nothing about digital humanities" (postdoc in history - Q3). Instead, the demand for digital methods came from supervisors:

Those digital methods were actually determined already by the project. Also, since I have a supervisor who is specialised in [this specific method of] analysis, I tried to, well, it was recommended by her.

( $\mathrm{PhD}$ candidate in history - Q4)

Several interviewees already had experience with digital practices, either through research projects conducted as an undergraduate or having worked on digital projects in cultural heritage. Yet what interests me here is that these findings counter the idea of digital history coming from the new generation of "digital natives" that intuitively use computers to conduct historical research, despite their more traditional professors. Within these case studies, digital history instead appears to originate from the opposite direction, through professors pushing their PhDs and postdocs to conduct digital methods.

A possible explanation for this is the wave of quantitative history from the 1960 s to 1980 s and the Dutch wave of alfa-informatics in the 1980s, as mentioned in the introductory chapter. With digital history reintroducing aspects of quantification and informatics, senior scholars who had been educated during those waves were interested in enlarging the scholarly community conducting practices they had been performing individually through the years. Consequently, advancing digital humanities was a reason mainly shared among the instigators. ${ }^{380}$ Some interviewees had ambitions with respect to the local university:

We want to have digital research in our faculty, the faculty [of humanities], here in the university. That is our first goal. But we also want to act as a point for collaboration between the different faculties. (coordinator with background in library science - Q5)

Other interviewees had ambitions on a national level:

380 Note that interviewees spoke of "digital humanities" rather than "digital history" specifically, in agreement with my characterisation of digital history as a field overlapping with the field of digital humanities. 
The goal is to advance digital humanities research in Belgium and to experiment with this more broadly.

(professor in computational science - Q6)

These ambitions commonly led to the reason of tool development, as an approach to advance digital humanities. This reason was shared among instigators and was the main reason for software developers. By developing tools and technological infrastructures, researchers inside and outside digital history would be facilitated with digital methods:

It is not the research itself that is the final outcome, but the components that come out that can be provided as a service to the faculty or the broader research community.

(professor in history - Q7)

This reason then emphasises the digital part of digital history:

It is of course technology-driven in the sense that without the new technology this project would not have started in the first place. You would not have thought about it then.

(professor in history - Q8)

In summary, the reasons for joining digital history collaborations were indeed technology-driven, as the above quote shows, to develop tools and advance digital humanities. Furthermore, reasons were related to enable the environment in which to collaborate with funding and a position to work at the university. Notably, historical research does not appear to be a direct reason to join a digital history collaboration, although it does become of importance in the individual goals.

\section{Individual Goals}

For the $\mathrm{PhD}$ candidates and their supervising professors, an important goal was to finish the thesis, continuing the somewhat pragmatic reason of acquiring a research position mentioned above. One professor said:

You cannot say 'well, I have software, I will provide that with my thesis, and I will have a $\mathrm{PhD}$ in digital history.' [. . .] What the historian must do is write a thesis with five chapters that are of substantial value to the [historical] field [. . . At the same time she uses digital means in her research.

(professor in history - Q9)

As can be seen in the above quote, the historical substance of the thesis was prioritised over the digital history ambitions of the collaboration. Another professor echoed this: 
In the last two years of the project we decided, very pragmatically, that ultimately the key outcome for the academics are those PhDs and the research. That is why everyone more or less continued from their own research question, without much further collaboration between the different institutes to work to more of a logistics or practical implementation.

(professor in computational science - Q10)

From these quotes, two characteristics of the $\mathrm{PhD}$ thesis become apparent. First, it is disciplinary, rather than interdisciplinary. Second, it is individual, rather than collaborative. ${ }^{381}$ As such, the project and the $\mathrm{PhD}$ are distinct paths, as explained by one interviewee:

What the PhDs do is that they are part of the digital humanities project, but I think that they are also just writing their $\mathrm{PhD}$, independent of that digital humanities project.

(coordinator with background in history - Q11)

One important rationale for separating a $\mathrm{PhD}$ thesis from a collaboration was risk aversion:

If [the project] fails, it cannot be that my thesis also fails. You can to some extent see them separate from one another, as I do. So, there is a sort of secret clause; if [the project] fails, I just graduate with a historical thesis.

( $\mathrm{PhD}$ candidate in history - Q12)

Some $\mathrm{PhD}$ candidates did try more explicitly to embed their thesis in digital history by making a methodological contribution. This individual goal could be described as advancing digital humanities, like the reason for joining with the same name. This goal was shared by some researchers in $\mathrm{PhD}$ or postdoc positions, as well as by instigators. One interviewee said:

[I hope] I can bring the crossroads between classical research and digital humanities into practice fairly concretely [. . . ] and bridge the gap with those who are not engaged in digital humanities.

(PhD candidate in history - Q13)

As with the reason to join, advancing digital humanities was related to tool development as a goal. This goal was mainly shared among the instigators of collaborations and software developers. The two goals were related insofar as the tool should demonstrate the utility of digital humanities:

The idea of the project has always been a proof-of-concept, a pilot of sorts or indeed a prototype that can be utilised more broadly. (coordinator with background in history - Q14)

381 These interviewed $\mathrm{PhD}$ candidates were in that sense similar to the $\mathrm{PhD}$ candidates that $\mathrm{I}$ described in my observations of the $\mathrm{C}^{2} \mathrm{DH}$ in the previous chapter. See also Fickers and van der Heijden, "Inside the Trading Zone.” 
While the tool was principally developed for the historians in the collaboration, the aim was that the tool could remain useful independent of their research:

[We are] developing a research environment, very concretely for this project, but it should be duplicatable to other projects. I think that is the most important aspect of what we want to do.

(coordinator with background in history - Q15)

The tools under development should, therefore, be applicable beyond the scope of the collaboration in question:

The challenge is to deliver a product that is useful for historians, but also valid towards [other disciplines].

(professor in history - Q16)

As demonstrators of the utility of digital humanities, another goal of importance was technological research, as can be discerned from the earlier quote Q8 of a project being technology-driven. This goal was shared by the instigators and the computational researchers. For several interviewees, this consisted of analysing the full text of sources to detect entities such as people, places or events and with those entities link sources and datasets:

My task was to see whether we could distil information from texts. For example, whether we can get events or people or points in time or locations from unstructured texts. [The idea was] to make a sort of event index, or to see here is a certain event in [this] collection, and here is an event in [that] collection, is it about the same yes or no.

(postdoc in computational science - Q17)

As with tool development, the applicability of the technology was broader than the specific scope of the collaboration. The technology under investigation not only concerned the historical research of the historians of the collaboration, but historical documents in general:

I am not interested in [the historical field] as such. My field is information extraction and text mining, and I have worked in various fields [of application] in the past [. . . The particular interest in these documents is that they are of a specific nature. They present particular challenges that you do not find in contemporary data. First, [with contemporary data], some of that is born-digital data, so you do not deal with transcriptions or OCR issues or whatever. Second, there is much more ambiguity and vagueness that is also related to the domain of history.

(postdoc in computational science - Q18)

The technological research was, moreover, broader and more ambitious than the specific implementation in the tool under development:

For me, the success of the project is basically building an interface where all this information is presented in a useful manner, where people can actually perhaps connect primary historical sources to secondary historical sources [. . . ] What I am doing might provide additional information to this interface from the original text sources that are not yet structured, 
that would be good, but it is not paramount for the success of the project. And it would be good for my personal research objectives, which are not directly connected to digital history objectives of course, but indirectly they are. (postdoc in computational science - Q19)

This interviewee decoupled the technology from the tool, reducing the tool to a graphical user interface to interact with the data. The interviewee thereby furthermore decoupled the technological research from the goal of advancing digital humanities. However, indirectly they are related, insofar as digital history is understood to concern technological progress in historical practices:

We also have databases such as [this collection], that is unstructured material. What if you want to link that meaningfully to the structured [data]? That is quite a step [. . .] Are we going to solve this? No. We really are in the prehistory, I would say, of this entire field.

(professor in history - Q20)

The technological research did stand in close relation with the goal using data. This goal connects with most of the other goals, as the sources are what the historian writes her thesis about, what the computational expert writes algorithms for (see quote Q18) and what the tool should make accessible. In quote Q2, the interviewee explained they wanted funding to work with their data. This goal is consequently shared by all participants of collaborations. For the historians, how they investigate sources was fundamental to their research and $\mathrm{PhD}$ thesis:

The project should not take an encyclopaedic approach. It is not just about storing information, but about aggregating a lot of information and asking new questions of it.

( $\mathrm{PhD}$ candidate in history - Q21)

For some interviewees, the data was crucial for the goal of advancing digital humanities:

[Digital humanities is about bringing] together corpora of sources, both texts as well as structured data. Not just within one's own institute, one's own university, research group, but far beyond, also internationally. Such collaborations have been announced many times in the past, but it is now that we finally have the means to do so.

(professor in history - Q22)

The data was usually provided by cultural heritage institutes, which were not formally participating in collaborations in most cases. The relation to these institutes differed between interviewees. In one collaboration, the coordinator took on the role of representing the cultural heritage institutes:

One of my roles is to represent the parties that act as data providers, and my point of view in all discussions is thus very data-driven, while our $\mathrm{PhD}$ candidate is very research-driven. She just wants information she can use for her research, and from the start we have debated how to bring those two together. (coordinator with background in history - Q23) 
Yet the work of cultural heritage institutes was also diminished by some as too limited:

The thing with archives is that they archive, they are not engaged with what researchers want to do with it for their research. (coordinator with background in history - Q24)

As such, participants argued to be more ambitious than the practices of cultural heritage institutes in unlocking the affordances of digitised data. The collaborations under investigation thereby indeed considered themselves as a balancing of the digital history duality with the digital, in computational research and tool development, and the historical, in historical research. Beyond this balance, the above quotes show how non-academic partners are included only in a role of service to the collaboration. Beyond the trading zone of historians and computational experts, these collaborations showcase a power asymmetry between academic partners as collaborators and cultural partners as passive data providers. These cultural heritage institutes consequently could not coordinate their goals and expected effects of providing the data. ${ }^{382}$

\section{Expected Effects of Participation}

Finally, participants coordinated activities and practices to fulfil what they expected to gain from collaboration. Following from the goal to finish the thesis, one expectation was the completion of PhDs. This expectation was similarly shared by PhD candidates and their supervising professors:

We have [several] PhDs now in a postdoc programme [. . . That is a nice result from this project, that we have given our PhDs the opportunity to grow, to take further steps in their career.

(professor in history - Q25)

One professor contrasted the importance of this incentive with that of tool development:

We are occupied with acquiring and managing projects rather than that we are doing research ourselves. With acquiring a project, it is also really the goal that the doctorates are defended and that publications come out. What is more or less a mismatch is that just

382 I can only touch the surface of this power asymmetry, since an in-depth exploration is beyond the scope of this book. For critiques of this power asymmetry see Reto Speck and Petra Links, "The Missing Voice: Archivists and Infrastructures for Humanities Research," International Journal of Humanities and Arts Computing 7, no. 1-2 (2013): 128-46, https://doi.org/10.3366/ijhac.2013.0085; Cook, "The Archive(s) Is a Foreign Country: Historians, Archivists, and the Changing Archival Landscape." 
implementing solid solutions based on technologies that have already proven their worth is perhaps not sufficiently innovative or original to get publications.

(professor in computational science - Q26)

This quote furthermore indicates that incentives were shaped by the expectations for future funding. This expectation, shared mainly by instigators, not only concerned future funding as an expectation in itself, but also the anticipation of what needed to be delivered from the current collaboration to qualify for future funding:

We more or less realised what we promised to realise. The doctorates are there, the publications are there. We will eventually also open up our dataset [. . .] I think that [the funder] will be satisfied.

(professor in history - Q27)

Another interviewee instead emphasised the tool as necessary for future funding:

One of the goals we have now set for ourselves is to bring our system to the attention of researchers and institutes related to the same type of research. That way we can try to get continued funding with them.

(coordinator with background in history - Q28)

This argument aligns with another expectation, that of tool usage. This expectation was mainly shared among the historians of a collaboration, in roles of instigators, $\mathrm{PhD}$, or postdoc. Although this is related to the earlier reason and goal of tool development, the participants are not the same. While tool development was associated with those on the providing side of the tool, the instigators and the software developers, tool usage was associated with those who received the tool to conduct research. Eventually, the historians were tasked with using the tool to investigate or demonstrate its utility:

Essentially, I am the guinea pig that has to show that one can do research with the interface and with the integrated data.

( $\mathrm{PhD}$ candidate in history - Q29)

Yet what I find significant is that this expectation is far more modest than the ambitions earlier in the collaboration. Rather than using the tool for research, it was limited to testing with a smaller case study:

Interviewer: Her role is limited to a use case considering how this works, what she can learn from it and how she can provide feedback to what you are developing?

Interviewee: Yes, and that is not meant to denigrate her role, but that is different from what we had envisioned from the start.

(coordinator with background in history - Q30)

In some cases, the system was not sufficiently finished to even conduct a test with a historical case study. A question might be what the collaboration had successfully achieved to support acquisition of future funding and continue in the field of digital history. However, rather than disappointment in failing to deliver a system, 
interviewees emphasised the success of the collaboration in the expected development of know-how. Insofar as collaborations did not entirely achieve their goals, this was pointed out to be an inherent risk of innovative research. In quote Q20 the research was described as a "prehistory"; experimental work conducted before a technology becomes entirely usable. Another interviewee argued:

In hindsight it was a bit too ambitious. But really, I am convinced that we are doing pioneering work.

(professor in history - Q31)

This expectation, shared by instigators, refers to the development of expertise in running interdisciplinary collaborations and learning from successes as well as failures. Know-how covered multiple facets of digital history, such as the technological approaches:

Ultimately a production-ready version does not have to come out of [the project], that is not the goal. This is more a technology project aimed at the know-how that is developed. [This is also useful for] the companies that continue to work toward a productive system, that they can use parts in a new product.

(professor in history - Q32)

Know-how also covered project management as an inherent aspect of digital humanities: ${ }^{383}$

Another thing is the learning process really. How do you conduct digital humanities? How do you bring these parties together, what do you run into? Everything that on a methodological organisational side succeeds or fails has to be put on paper. (professor in history - Q33)

Finally, development of know-how covered working with the data:

In historical research, of course, the by-catch is always at least as important as the envisioned goal. By making the texts available we ran into problems that exist elsewhere too and that have not yet been solved in the field.

(professor in history - Q34)

The last quote furthermore points to the expectation of a transformed dataset. Independent of specific tools or methods, collaborations provided a new dataset by having linked or enriched existing datasets. This expectation was related to the goal of using data, but while that goal was shared by all participants, here it was mainly shared among the instigators. The transformed dataset was an explicit

383 For more on project management as an inherent aspect of digital humanities, see Anna Maria Neubert, "Navigating Disciplinary Differences in (Digital) Research Projects Through Project Management," in Digital Methods in the Humanities, ed. Silke Schwandt (transcript Verlag, 2020), 59-86, https://doi.org/10.14361/9783839454190-003; Lynne Siemens, "Project Management and the Digital Humanist," in Doing Digital Humanities: Practice, Training, Research, ed. Constance Crompton, Richard J. Lane and Raymond George Siemens, 1st edition (New York, NY: Routledge, 2016), 343-57. 
deliverable of collaborations, usable for others: "our data [. . .] is very complete, so it can be used as a ground truth set for future research" (professor in history Q35). While the delivered tool may or may not receive continued development, historians could use the existing facilities to keep expanding their dataset:

[The platform] is still in progress, there is not really an end to it. We can keep on adding data for years to come.

(professor in history - Q36)

The dataset was as such a fairly stable deliverable, enabling future research.

Finally, most participants shared the expectation of methodological innovation, whether or not the tool would be usable for the historical research. For some, it referred to facilitating new methods:

Can the researcher do more than they could before? I find that very important. I find it pleasing when I can look back and think I have done something new in this project for myself and really learned something.

(software developer - Q37)

In several cases, the increased ability of the researcher referred to the ability of examining more source material:

I have consulted a larger dataset than [another researcher] ever could, simply because I had digital accessibility of sources [. . .] So I think I took an older method into the $21^{\text {st }}$ century.

$(\mathrm{PhD}$ candidate in history - Q38)

In summary, expected effects were both individual, such as completing one's $\mathrm{PhD}$ thesis, but also extended to the research community more widely, bringing methodological innovation or a dataset for others to build upon.

\section{Grouping Incentives}

From the interviews I have identified 15 different reasons, goals and expectations that shaped practices at different points of collaborations. When connecting these reasons, goals and expectations, several underlying incentives emerge. For example, the reason to acquire a research position, the goal to finish the thesis and the expectation of completion of $\mathrm{PhD}$ are arguably continuations of the same incentive: that one wants to conduct and complete research. Grouping incentives as such, I distinguish six categories of incentives: 1) funding, 2) digital history/humanities (DH), 3) data, 4) tool development, 5) historical research and 6) computational research (see Table 3).

These incentives are intuitive for digital history. If the goal had just been to uncover these incentives, I may not have needed to go through the different reasons, goals and expectations. Yet it is to be expected that not all incentives can 
Table 3: Grouping of incentives. Phrasing of incentives shortened to fit the table.

\begin{tabular}{|c|c|c|c|}
\hline INCENTIVE & $\begin{array}{l}\text { REASONS FOR } \\
\text { JOINING }\end{array}$ & INDIVIDUAL GOALS & $\begin{array}{l}\text { EXPECTED EFFECTS OF } \\
\text { PARTICIPATION }\end{array}$ \\
\hline FUNDING & $\begin{array}{l}\text { Acquire funding } \\
\text { (instigators) }\end{array}$ & & $\begin{array}{l}\text { Future funding } \\
\text { (instigators) }\end{array}$ \\
\hline $\mathrm{DH}$ & $\begin{array}{l}\text { Advancing } \mathrm{DH} \\
\text { (instigators) }\end{array}$ & $\begin{array}{l}\text { Advancing } \mathrm{DH} \\
\text { (instigators, } \mathrm{PhD} \\
\text { candidates, postdocs) }\end{array}$ & $\begin{array}{l}\text { Methodological } \\
\text { innovation (all) } \\
\text { Development of know- } \\
\text { how (instigators) }\end{array}$ \\
\hline DATA & & Using data (all) & $\begin{array}{l}\text { Transformed dataset } \\
\text { (instigators, } \\
\text { computational } \\
\text { researchers) }\end{array}$ \\
\hline TOOL & $\begin{array}{l}\text { Tool development } \\
\text { (instigators, } \\
\text { software developers) }\end{array}$ & $\begin{array}{l}\text { Tool development } \\
\text { (instigators, software } \\
\text { developers) }\end{array}$ & Tool usage (historians) \\
\hline $\begin{array}{l}\text { RESEARCH } \\
\text { (HISTORICAL AND } \\
\text { COMPUTATIONAL) }\end{array}$ & $\begin{array}{l}\text { Acquire position } \\
\text { (PhD candidates, } \\
\text { postdocs) }\end{array}$ & $\begin{array}{l}\text { Finish the thesis (PhD } \\
\text { candidates, professors) } \\
\text { Technological research } \\
\text { (instigators, } \\
\text { computational } \\
\text { researchers) }\end{array}$ & $\begin{array}{l}\text { Completion of PhD } \\
\text { research } \\
\text { (PhD candidates, } \\
\text { professors) }\end{array}$ \\
\hline
\end{tabular}

be pursued equally. A collaboration ultimately has to prioritise incentives and decide whether the challenges of one can be handled by decreasing attention to another. By taking this bottom-up approach, it is possible to describe who in the collaboration is related to which incentives.

For the first four incentives, funding, DH, data and tool development, the main participants are the professors in history leading the collaborations and the coordinators. Together, these two types of participants formed the collaboration instigators. The incentive tool development was also held by the software developers. However, in these case studies the software developers were hired and did not actively try to shape the collaboration. It can thus be argued that these four incentives were all held by the same community of practice, in the sense that this was a community of like-minded participants that aimed to align the practices of the collaboration to their incentives. I call this community the collaboration instigators. When interviewees spoke of "the project", it was commonly in reference to these four incentives. The instigators thereby aligned the project with their individual incentives. 
For the final incentives related to research, two communities become apparent. The first community is related to historical research, with the main participants the $\mathrm{PhD}$ candidates and postdocs and their supervising professors in history, who also led the collaboration. I refer to this community of practice as the historians. Note that this community did not include the coordinator. Although most coordinators had a background in history, the coordinator was not responsible for the historical research. As such, in some cases the coordinator would oppose historians in their incentives to shape the collaboration toward the historical research. This is exemplified by quote Q23, where the coordinator explicitly took on a data-driven position against the research-driven position of the $\mathrm{PhD}$ candidate in history.

The other type community is related to computational research, where the main participants were the computational researchers and the instigators. I call this community the technologists, since they emphasised the technological aspects of the collaboration. Note that this community not only included computational researchers, but also the historians in senior positions and coordinators that desired to advance digital history through the development of technology, as exemplified by quote Q8.

In summary, three communities emerge through the identification of communities holding similar incentives: collaboration instigators, historians and technologists (see Figure 6). Of significance is that while some collaboration participants align with a single community, others are part of multiple communities. Notably, the professor in history leading the collaboration is part of all three and is the bridge between all the different incentives.

\section{Crossing Boundaries}

In several interviews, professors emphasised the need to have coordinators in the collaboration to "get everyone on the same page". Yet the above analysis of incentives showed that coordinators did so by emphasising the incentives of the

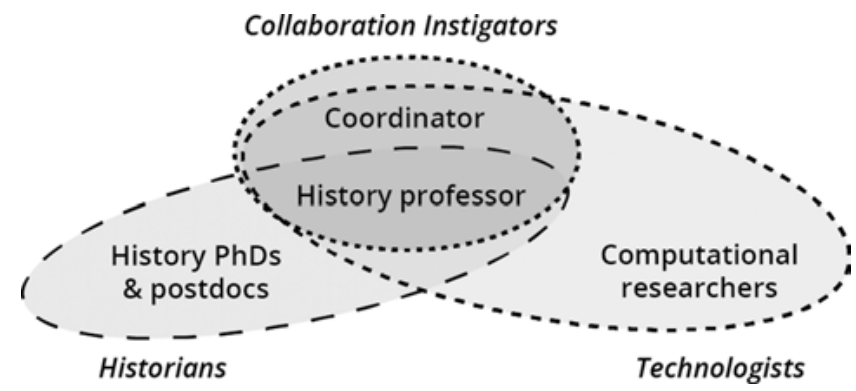

Figure 6: Communities of practice holding similar incentives. 
collaboration instigators, such as tool development and data transformation. Furthermore, while coordinators had more time to keep an eye on progress, they did not usually have the power to decide which direction to take. For that coordinators were dependent on the professor in history. As such, the academic hierarchy power mechanism affected the practices of coordinators:

In a certain hierarchy, she was lower in the sense that she was not a $\mathrm{PhD}$ nor a professor. She was just someone hired to do the job. She could not say [to the professor] I need this, and [to the $\mathrm{PhD}$ candidate] I need this.

(postdoc in computational science - Q39)

Yet even for the professors this could prove difficult, especially in collaborations with multiple professors from multiple institutes:

It is quite difficult to do, because she is not the boss of [the other professors]. There was no project leader telling everyone what to do. (postdoc in computational science - Q40)

In such collaborations, which occurred when collaborations occurred between different research groups or institutes, the professors experienced symmetric power with respect to their academic positions.

The professors arguably took on the role of what Étienne Wenger called the "broker" between multiple communities of practice, or what Jennifer Edmond called the "digital humanities intermediary". ${ }^{384}$ That is, they coordinated and introduced practices or incentives from one community of practice into another. This is a significant new role for the professor in history, and one I return to later in the final chapter.

To further understand how incentives were negotiated between these communities, in the next section I investigate situations of conflicting incentives.

\section{Conflicting Incentives}

I distinguish six different incentives held by participants of the collaborations. Each of these incentives may oppose one another. In this section, I highlight situations where one incentive conflicted with another, to gain insight into the process of coordination and the power relations that become visible through these conflicts. Interestingly, no conflicts with the incentive digital history became apparent in this study. While this may be because most participants aligned with this incentive, the primary reason for this absence seems to be that digital history

384 Wenger, Communities of Practice, 108-10; Edmond, "The Role of the Professional Intermediary in Expanding the Humanities Computing Base." 
as an incentive was approached through other incentives such as tool development or data. These incentives that needed to be conducted first then led to conflicts within the collaborations as described below.

\section{Historical Research \& Computational Research}

The first conflict is perhaps the most intuitive in the context of digital history: the opposition between the digital and the history. For the historians the historical research took priority over the computational research. This was especially clear with the goal to finish the thesis, where historians considered their thesis independent of the technology under development. Historians thereby detached their research from the technological research:

It is usually [them] that ask me to reflect on what they have created or what I think of a certain plan they have, rather than the other way around, because I can usually work fine without their input.

( $\mathrm{PhD}$ candidate in history - Q41)

To the extent that the two incentives were connected, historians saw the technology in a facilitating role:

Everything that happens ultimately has the goal that I can do better research [. . . The programming work I see as a sort of facilitating matter.

( $\mathrm{PhD}$ candidate in history - Q42)

Moreover, when the computational experts required input from the historians, the latter did not see this as part of their research:

She does not really realise that the problem she is modelling and the way that she tries to structure the information actually consists of a vital part of research as well. She does not see this as research. She still sees that the main output of her research is the historical research.

(postdoc in computational science - Q43)

Yet if the collaboration would entirely prioritise the historical over the computational research, this would entail the use of readily available technology:

If you want to make a tool that a historian will trust for their own research, then most people use methods that are well-defined [. . .] or very basic things that are robust. These things work and are well-tried. Now if you want to go a step further [. . . ] there is a higher risk and a higher uncertainty about the results. That is why I am not sure whether this tool will be readily usable.

(postdoc in computational science - Q44)

As it was not satisfactory for collaborations to lack technological innovations, the computational research did not always succumb to the desires from the historians. At several times, the technology was prioritised over the requirements for historical research. For example, in one case a historian tried to limit the scope of the 
technology to the scope of her historical research. The technologists did not follow this line, as they considered this an unsustainable route:

Did you think of the consequences for the future [. . .] You cannot just take parts out [. . .] That would be a decision that no longer allows you to do other things in the future.

(professor in history - Q45)

For the historians it could consequently become increasingly difficult to continue negotiation with the technologists:

When there is a functionality available, I can do something with it and we can take the next step as far as I am concerned. Yet for her it often seems more of a discussion on a philosophical level. Sometimes that surpasses me. The back-end remains something I feel I cannot do much with.

$(\mathrm{PhD}$ candidate in history $-\mathrm{Q} 46)$

What is of interest in this conflict is the extent to which historians were implied to not properly understand the technology, and how that configures the conflict. Attempts by historians to shape the practices of technological research were consequently hampered due to a lack of expertise of what this incentive entailed. In the opposite direction, historians would detach the historical research from the technological research, so that only they could shape their own practices of historical research.

\section{Historical Research \& Tool Development}

The second conflict, between the tool development and the historical research, is probably as intuitive to digital history as the first. This conflict was partially caused by promises made in the grant application:

The promise you make to [the funder] is that you say, 'we will do historical research and that is input for the tool development, and what I can do with the tool is input for my historical research.' But in our case, it turned out that does not really work in practice. [The $\mathrm{PhD}$ ] has almost finished her thesis, and there is very little that she discovered by actually using [our tool].

(coordinator with background in history - Q47)

The second aspect, where the historians could use the tool for their research, proved difficult under time constraints and delays in development. Consequently, historians would again detach their research from the tool development:

Each historian works individually on their own little island, that practice is hard to change. We still notice that the PhDs affiliated with the project also prefer to set up their own little data collection, on their own hard drive, rather than sharing everything. And there is a reason why they do that. The infrastructure [. . . is far from where we are supposed to be. 
Another problem that emerged was that some participants lacked interest in the technological goals of a collaboration and how those come to fruition. For example, one interviewee argued that how a tool functions is not of concern to historians:

We did not say how it should work technically, because in principle for us the technical side should not be relevant to the end-user, as long as the tool works.

(coordinator with background in history - Q49)

Yet how tools work on a technical level and whether they work well for historians cannot be considered strictly independent. In several cases the tool development was not intentionally prioritised over historical research, yet the way historical research could be conducted was shaped by decisions made with respect to the tool. For example, the data model of a tool required historians to provide their data in a certain way:

The data design of the structured environment is fairly complex, it includes a lot of objects and sub-objects and object descriptors. We had to put all our data in the proper format.

(professor in history - Q50)

Historians tried to shape tool development by providing functional requirements. Yet the communication and coordination of those functionalities proved more complex than anticipated:

We thought [the software developers] were experienced and knew what we meant. We did not consider that our requests could be interpreted otherwise.

(coordinator with background in history - Q51)

In this case, a mismatch occurred between how historians described a functionality and how developers interpreted that functionality in code. As the developers had technically satisfied the requirement, it was contractually difficult for the historians to further shape the system. Further adjustments required additional budgeting, which was lacking. Another dependency that was not anticipated by historians was the time required to develop functionalities:

There is absolutely a disconnect between how we want to use the tools and the time that is needed to develop that. We do not have a good handle on how long any given request takes to translate into code.

(postdoc in history - Q52)

Once a tool was created and made available to historians, yet another dependency was the performance of the tool. In one collaboration, the tool was hosted by the computational researchers. Yet the server was used by multiple research projects. When another project ran their experiments, the historians' tool crashed or operated so slowly it was deemed unusable. According to the coordinator of 
this collaboration, after the historians complained they wanted better support, the computational researchers simply replied with "no, that server is for multiple experiments, you are just one of the experiments" (coordinator with background in history - Q53). The PI of this project underscored the historians' dependency on the expertise of computational researchers:

You are very dependent on what the computational researchers as experts, which they are, say and argue should be in the project proposal [. . . In hindsight I think they should have said more about the really practical things, such as computation capacity, server space, the stability of software, how that is managed. You need money for that too. We did not have budget for that in the project, as idiotic as that seems now. (professor in history - Q54)

Finally, even when a tool was delivered and performed well, the practice of continued development conflicted with the expectations of historians that the same action should lead to the same results:

A very sleek and finished looking tool makes you think as a user that it is finished. But we know that it is constantly being tinkered with under the hood. The collections and the number of [sources] that we are dealing with are constantly changing.

(postdoc in history - Q55)

In this conflict of incentives, it is of interest that again the extent to which historians' lack of understanding computational practices shaped the conflict. Ignorance of how long development takes, how a tool is hosted, or how a feature request is interpreted and how those factors affect performance and usability led to tools that did not meet the expectations of historians. As such, the historians were dependent on the computational researchers and software developers to bring about usable systems. Here too, historians consequently detached the historical research from the tool development, so that the historical research was not shaped too much by the tool. Historians especially tried to secure their research from failing when the tool did not meet expectations or arrived too late. As such, this detachment should be seen as a risk aversion strategy.

\section{Computational Research \& Tool Development}

That there is a conflict of incentives between the tool development and the technological research may be less obvious of digital history. One might expect that these two incentives refer to the same aspect of the collaboration, namely the overall development of a digital method for the historians, the "digital" in digital history. Yet in quote Q19 the computational researcher separated the incentives. Where the technological research is innovative and carries risk of failure, the tool should be stable and usable, as argued in quote Q44. For the historians 
this detachment could prove problematic, as this meant that the computational researchers prioritised their own research agenda over the project's goal of facilitating historical research with a tool.

This conflict of incentives is, therefore, perhaps the most fundamental to digital history collaborations. The detachment of tool development from technological research means that the vision of historical researchers and computational researchers collaborating toward a common goal might not work out as hoped:

The usual clash at risk is that I want something and that [the computational researcher] says 'I can do that with one hand tied behind my back. At an academic department in computer science that is not interesting for me. That is not innovative'.

(coordinator with background in history - Q56)

To counter problems arising from this detachment, and to ensure that the tool development would commence, tasks were separated between computational researchers and software developers. While the computational researchers would provide input for tool development, the responsibility to deliver a working tool lay primarily with the software developers. Furthermore, other tasks related to the tool were delegated to IT personnel in the university or the university library:

You need someone in-house who can maintain the server, because the programmer you asked for that usually does not have the skills or the desire to, or their time is too valuable [. . .] It took a while before we found the right person here in the university who would do that as part of their job.

(coordinator with background in history - Q57)

In this conflict of incentives, computational researchers detached the technology from the tool in order to focus on their research and publications, rather than maintaining a stable tool. Consequently, the digital history collaborations in my investigations distributed non-research tasks to partners such as software developers, IT personnel, or librarians. This detachment too can be seen as a risk aversion strategy, to secure the goal of the collaboration to provide a tool. In case the technological research succeeds on time, it can be implemented in the tool. If the research however fails or is delayed, the tool can still be delivered without the innovative technology. In this case, as exemplified in quote Q19, the tool is reduced to an interface to the data, which brings me to the next conflict of incentives.

\section{Data \& Tool Development}

In the grouping of incentives, I identify both data and tool development as belonging to the same participants of a collaboration, namely the collaboration instigators. Moreover, I found that the tool was essentially seen as a gateway to 
the data (see quotes Q19 and Q29). There should not be a conflict of incentives. However, integrating the data in the tool proved to be complicated. A major stumbling block was the processing of large amounts of data. This took more time than anticipated, introducing delays. One collaboration consequently significantly adjusted their goals. Originally, the collaboration was to investigate a transnational history, but instead they could only work with data relating to a single nation:

It started with these grand ambitions, with sources from all different countries. They never materialised, mostly because of copyright problems, but also because of the actual amount of time it takes to get them into the right format to even go into our database. [. . . ] Now the project is about Dutch history instead, because those [sources] have already been digitised.

(postdoc in history - Q58)

When collaborations succeeded in importing data in the tool a consideration was how the tool transformed the data, as certain aspects of the data would be emphasised or hidden. A common issue was the role of optical character recognition (OCR), which is never perfect and can thereby obscure some sources from view. ${ }^{385}$ For example, when some sources are not machine-readable, but others are, only the latter sources will be usable in the tools under development.

Another issue for collaborations that connected multiple datasets was how to treat parts of a dataset that were not connected to another dataset. In one case, this led to a system where items that were not in multiple datasets could no longer be retrieved:

When you searched you would only find [items] that were in two or three or more databases. If you would add information at a later time, you could no longer access the largest database to extract information, because those links had not been made.

(coordinator with background in history - Q59)

In this situation, the collaboration had to coordinate whether to emphasise the objects or the links between objects, with significant consequences for how historians could use the system for their research. Eventually, they had to rebuild the system entirely to emphasise the objects themselves, rather than the relations between objects.

In short, while data and tool development were not opposed as incentives, the integration of the data and implementation of the tool affected one another,

385 Optical character recognition (OCR) is an essential step in transforming historical sources into machine-readable data. The performance of OCR thereby shapes the validity of historical research using computational means. For critical discussions see Jarlbrink and Snickars, "Cultural Heritage as Digital Noise"; David A. Smith and Ryan Cordell, "A Research Agenda for Historical and Multilingual Optical Character Recognition” (NUlab, Northeastern University, 2018). 
introducing unintended trade-offs. First and foremost, the integration of data proved much more time consuming than anticipated, leaving less time for tool development, or significantly altering the tool. Second, decisions made in the tool could emphasise or obscure data unintentionally, leading to the next conflict.

\section{Data \& Historical Research}

The relevance and quality of the data was the key issue for the historians. Even if the tool would work as envisioned, the historians could not conduct proper research without data of interest:

You remain dependent on the substance and quality of the data that is provided by the project partners. Even with a magnificent system, with everything visualised, it is quite possible that the relevant information is simply not in the data. (PhD candidate in history - Q60)

Furthermore, interviewees discussed cases where data fit the tool under development rather well. Yet in these cases they were critical of how this introduced a bias, as the tool emphasised the data that worked well with the tool, rather than the data that did not:

The Leeuwarden newspaper has been OCRed and digitised very well, for several hundreds of years. A lot of studies consequently refer to the Leeuwarden newspaper and not to other newspapers. The risk is that for the next ten years there is a bias for Leeuwarden in historical studies.

(postdoc in history - Q61)

Historians thus remained well aware of the limitations of certain datasets. Some feared that historical research would be biased in ways that do not correspond to the true importance of historical events or objects, like the Leeuwarden newspaper. ${ }^{386}$ Yet by conducting historical research as part of a collaboration that is supposed to work on certain data, historians were expected to do research with these datasets. One interviewee was especially critical of their data, saying "nobody would ever choose these sources if they had a choice" (postdoc in history Q62). Instigators, therefore, had to coordinate the balance between the historical

386 For discussions about biases in historical research following digital availability, see Ian Milligan, "Illusionary Order: Online Databases, Optical Character Recognition, and Canadian History, 1997-2010,” Canadian Historical Review 94, no. 4 (2013): 540-69, https://doi.org/10.3138/ chr.694; Kobie van Krieken, "Using Digital Archives in Quantitative Discourse Studies: Methodological Reflections,” Tijdschrift Voor Tijdschriftstudies 38 (2015): 43-50, https://doi.org/10.18352/ts. 343; Thomas Smits, "TS Tools: Problems and Possibilities of Digital Newspaper and Periodical Archives,” Tijdschrift Voor Mediageschiedenis 139 (2014): 139-46. 
research and the work on the dataset, so that data deemed not of interest by historians would not be discarded too hastily.

Historians also extended their research beyond the data worked on by the collaboration. For the instigators, this could be unsatisfying, as it meant historians built their "own little data collection" (quote Q48). Yet in the role of supervising a $\mathrm{PhD}$, professors acknowledged the necessity of using data that may not be digitised yet:

She also works in the paper archives [. . . ] like all of us historians. I too have worked in the archives, doing the diligent manual work. (professor in history - Q63)

What this quote furthermore exemplifies is that even for historians with a digital focus, working with material sources in archives remains part of the expected historical process. ${ }^{387}$ This expectation to work with data that was not yet digitally available led to requests for functionality to add one's own data into a tool. In one collaboration, historians emphasised the need for the data model and tool to allow working with incomplete data and the ability to add data later on:

We as $\mathrm{PhD}$ candidates in history were looking for an environment where, before you have a [complete dataset], you can already start enriching the available data.

(PhD candidate in history - Q64)

The historians in $\mathrm{PhD}$ and postdoc positions were tasked to work with the data, yet saw their research in a wider context than the collaboration. Ultimately, historians took a question-driven approach, cherry-picking relevant data from the datasets and acquiring additional data from other sources. In contrast, instigators took a data-driven position to ensure the datasets were still used, as exemplified by quote Q23.

\section{Data \& Computational Research}

Data also proved a stumbling block for computational research. Computational researchers were accustomed to starting a research project with a fairly clearly defined dataset that fit the proposed research method. In digital history collaborations, this was not the case:

[The cultural heritage institute] said 'yes we have data'. As it turned out they had a nice shelf with handwritten books. (postdoc in computational science - Q65)

387 See also Gerben Zaagsma's argument that historical scholarship in the digital age is "hybrid" by nature, combining digital and traditional methods. "On Digital History." 
In another collaboration, the data was available in digital form, but still not immediately suitable for computational approaches:

When you investigate the dataset, row by row [. . . ] you discover that those datasets contain big errors or that entire columns are wrong. Sometimes you have to leave data out because it is only comprehensible to the person who created the dataset.

(coordinator with background in history - Q66)

In one case, the computational researcher ultimately resorted to readily available datasets, rather than the dataset that was worked on in the collaboration. Because the computational researcher was then no longer working on the same dataset as the historians, the historical and computational research drifted apart. In the eyes of some historians, the computational research then lost its purpose and value:

[They] did not collaborate with the historians working on the project. There was no real research question, no real feedback to a historical research question.

(professor in history - Q67)

While the "ambiguity and vagueness" (quote Q18) made digital history interesting for computational researchers, it also introduced risks. The data may end up being inadequate for the collaboration to implement the envisioned technology, at least not without intensive additional work. As a result, some computational researchers detached their research from the collaboration goals to work with a specific dataset, and acquired data that facilitated their research better.

\section{Funding}

Finally, an important influence on the collaboration is the funding. I identify funding as an incentive especially for collaboration instigators. In the expectations I found that instigators tried to shape the project to meet the funders' demands both for the current and future grants. It can thus be argued that funders shaped collaborations from the outside. One interviewee mentioned that funding was what necessitated collaborations in the first place. With funders increasingly requiring interdisciplinary collaborations in teams, historians see themselves pushed toward such collaborations, whether they want to or not:

You now forge unorthodox alliances because the knife is on the throat. You have to be able to look beyond borders to keep along.

(professor in history - Q68)

Following such requirements from funding organisations, another historian expected that they could only acquire funding by focusing on digital history: 
I do not think I would ever get a grant as a philosopher of history. If I ever want to get a grant for anything, my only option is to do that on digitisation. (professor in history - Q69)

Digital history collaborations are expensive, however, reinforcing the need to keep applying for funding:

You are continuously short on money, so you have to continuously apply for grants to go further.

(professor in history - Q70)

Digital history is expensive for several reasons. A common reason is that the collaborative aspect is expensive, requiring personnel to conduct the proposed research. Another expense is the investment in experimenting with unstable technology. While one could object to this practice and argue that historians should wait for technology to stabilise before historians invest in a technology's application, one interviewee argued this is a good thing:

I have seen how much money just drained away, because the technology was followed while it was still undergoing so much maturation. At the same time, I do not criticise that, because that means that demands have been made of it, and that the development is known.

(professor in history - Q71)

Thus, this historian argued that by engaging with the technology during its maturation, historians can try to influence the technology to fit their needs and better steer the development to align with their demands. Historians are moreover better able to understand how a technology came to be and how it works. While this may require significant investments, the end result is that the technology is hopefully better suited for historical research than if historians had not participated during its development.

Apart from enabling historians through grants, funders simultaneously limited what can be done with a grant. While funders promote collaboration and the development of digital systems, historians criticised the lack of adequate funding for software development:

There is very little money available for software development, while this kind of project really run[s] on good people with high work rates [.. .] The best programmers are at private companies, who pay a lot more. And [the funder] does not really consider that.

(coordinator with background in history - Q72)

Funders furthermore did not always consider sustainability, instead limiting the scope of grants to innovative research. Collaborations consequently did not have a clear picture of how they could continue work on the system that was developed, since the national funder did not provide grants for sustained development: 
[The PI] would like to continue this course, but the tricky thing is, and everybody is confronted by that with [the funder], that they do not fund continuation projects, only new innovative things.

(coordinator with background in history - Q73)

Finally, funders limited the outcomes of coordination. That is, through coordination and the experiences of the collaboration, scholars might discover that their initial idea could be improved. Yet funders did not allow too much deviation from the initial proposal:

If I would write the project proposal now, I would do a number of things entirely differently. But the proposal has already been written and [the funder] only allows minimal deviations, so you sort of have to do it the way you wrote it.

(coordinator with background in history - Q74)

While funders enabled digital history collaborations, they simultaneously confined what could be done in these collaborations, limiting the decisions that could be made through coordination. Since collaborators anticipated the need for future funding requests, they furthermore had to ensure the current collaboration was satisfactory to funders to sustain a good track record. Funders were not part of the collaboration and were not actively part in the meeting between historians and computational experts. However, from the outside they are important actors that affect the field of action of digital history collaborations for both participating historians and computational experts.

In the next section, I conclude this chapter to consider how the different actors discussed in this chapter, both within and outside the collaborations, negotiate power relations.

\section{Power Asymmetries of Digital History Trading Zones}

In this chapter, I investigate how power relations affect the negotiation of practices in digital history trading zones. As introduced in the second chapter, I consider two dynamics of power relations. First, the extent to which participants in a trading zone constrain or enable the actions of other participants. Second, the extent to which participants in a trading zone are able to define their own boundaries of action. Power relations in trading zones are thereby defined as the extent to which some participants are less able to shape their own field of action, and where one party is able to shape the field of action of the other party to a greater extent than vice versa. By analysing how the different communities of practice within these collaborations coordinated conflicting incentives, different practices of shaping fields of action become visible. 


\section{Shaping One's Own Field of Action}

For the first dynamic of power relations, the ability of participants to shape their own field of action, I observed that historians detached their objectives from the objectives of the collaboration instigators and the technologists. This is a significant activity that goes beyond a mere disagreement of incentives. Historians did not only prioritise their historical research over the tool development and technological research, which may be expected. I moreover find that historians conducted their research parallel to and independent of the outcomes of the tool and technology, as exemplified by quote Q41. Historians did not require the technology nor the tool under development to be able to conduct their research. Furthermore, when historians used the dataset worked on by the collaboration, they took a question-driven approach, cherry-picking data deemed of interest to their research, and acquiring additional data from other sources (e.g., see quotes Q23 and Q60). As such, historians shaped their field of action to fit their conceptions of what makes good historical research, in order to be able to finish their research. This historical research must conform to the disciplinary values of history, and should be conducted individually, especially in the case of a $\mathrm{PhD}$.

Yet not only historians shaped their fields of action as such. Computational researchers also detached their computational research from the objectives of the collaboration instigators, and thereby indirectly from the historians. Computational researchers stressed their work was research, which may or may not result in a usable technology. Consequently, they argued that the tool development should not depend on the technology (quote Q19). Furthermore, they argued if tools should be readily usable, the collaboration could better implement stable technologies rather than technologies under investigation (quote Q44). As such, computational researchers shaped their fields of action to remain research according to their disciplinary values, rather than software development or maintenance (e.g., see quote Q56).

Both detachments can be seen as risk aversion strategies, since failure or delay of the technological research should not lead to a failure of the tool development. Failure or delay of the tool development should likewise not lead to a failure of the historical research (see quote Q12). It is for this reason that the professor in history, part of all three communities holding incentives, allowed this detachment to take place. Participants were thus fairly successful in shaping their own field of action according to their communities' incentives. 


\section{Shaping the Other's Field of Action}

Participants of collaborations also tried to shape the fields of action of their collaborators and vice versa, the second dynamic of power relations. Historians in $\mathrm{PhD}$ and postdoc positions saw their fields of action shaped by their supervisors, the professors in history. Having applied to a research position, their supervisors recommended methodological approaches that fit the goals of the collaboration. Supervisors in the role of collaboration instigators recommended the PhDs candidates in history to use digital methods determined by the collaboration (quote Q4) and asked not to set up one's “own little data collection” (quote Q48). Yet as part of the detachment of historical research from the tool and technology, supervisors recommended that $\mathrm{PhD}$ candidates in history ultimately needed to produce a historical thesis (quote Q9) and the disciplinary value of working not just with digital data, but also with "paper archives" (quote Q63).

Even though historians detached their historical research from the tool development and computational research, they communicated their requirements in the hopes of steering development. Historians thereby tried to shape the fields of action of the collaboration instigators and the technologists. Furthermore, in response to the detachment of computational researchers from the tool development, collaborations hired software developers or contacted IT personnel for sustaining tools. By relying on a commercial or supporting party, collaboration instigators hoped that they could shape the software development without being confronted with opposing incentives, as seen in quote Q56. However, these attempts at shaping were ineffective. Instigators did not adequately anticipate the interpretation of feature requests (quote Q51), the time required for implementation (quote Q52), nor the costs of sustained performance (quote Q54). In all these cases, the historians received a tool that did not facilitate their research as envisioned.

As such, the envisioned power relation of historians influencing the work of software developers and computational researchers was overturned. Historians had insufficient insight in the fields of action they tried to shape. Historians lacked knowledge of the practices of software developers and computational researchers to effectively shape those practices. This lack of expertise in the practices of collaborators has been called knowledge asymmetry. ${ }^{388}$ The division of tasks in a collaboration is related to the division of knowledge, but this introduces

388 Anurag Sharma, "Professional as Agent: Knowledge Asymmetry in Agency Exchange," Academy of Management Review 22, no. 3 (1997): 758-98, https://doi.org/10.5465/AMR.1997. 9708210725. 
the problem that one participant may not be able to evaluate the contributions of another participant. As a direct result of cross-disciplinary interactions, where participants have limited insight into other collaborators' disciplinary knowledge, I call this "interdisciplinary ignorance". Lacking knowledge of how computational experts performed their tasks, historians were unable to shape the field of action of computational experts, putting the latter in a more powerful position. Knowledge asymmetry consequently led to power asymmetry.

An additional problem for the historians was that this did not hold true in the other direction. Historians as end-users were dependent on software developers and computational researchers as system designers. ${ }^{389}$ In cases where the software developers lacked understanding of historical practices, e.g., by misinterpreting feature requests (quote Q51), this meant that the results were not to the satisfaction of the historians. The existing dependency of historians on computational experts put historians in a less powerful position. Knowledge asymmetry reinforced this power relation, as historians could not adequately shape the fields of action of the computational experts. It could be argued that this is why collaboration instigators emphasised the development of know-how, so that in future collaborations knowledge asymmetry and resulting power asymmetry may be decreased significantly. I return to this matter in the next chapter.

Finally, in the attempted shaping of the fields of action of collaborators, it becomes visible how engagement configured power relations. In the previous chapter, I noted that humanities scholars tend to outnumber computational experts in collaborations suggesting a possible power relation. Yet in the current chapter, I find disciplinary diversity led to conflicts of incentives, such as between the historical and the computational research. However, a majority of historians as participants did not guarantee a power relation to the advantage of the historians. I find existing power mechanisms such as the dependence of historians on the computational experts and the power balance between professors supervising the research groups granted computational researchers the autonomy to detach research objectives when needed. Furthermore, knowledge asymmetry put computational experts in a more powerful position. Moreover, I noted in the previous chapter that collaborations tend to be conducted on a large physical distance. With increased physical distance, it was easier for participants to detach their objectives and more difficult to hold collaborators accountable. With irregular communication it was more difficult for collaborators to remain cognizant of the practices of collaborators, limiting the ability to shape the fields of action of collaborators. Distance thereby reinforced knowledge asymmetry. In

389 Markus and Bjorn-Andersen, "Power Over Users: Its Exercise By System Professionals.” 
short, with increasingly distant engagement, coordination became increasingly difficult, especially to the disadvantage of the historians.

\section{External Shaping}

Finally, not only did participants within a collaboration coordinate practices with one another; they saw their practices influenced by external parties. The most significant external party shaping the field of action of the collaboration was the funder. Funders published calls for grants to which the collaboration must fit their research ideas, pushing for collaboration and innovation (e.g., quotes Q1, Q68, Q73). Yet perhaps most significantly, by working with a grant, collaborations were tied to specific time frames. ${ }^{390}$ Collaborations struggled to conduct historical research with a tool that needed to be built from scratch in the same time period, as exemplified by quote Q47. In the first two case studies, the collaboration lasted four years, just as the $\mathrm{PhD}$ positions. In these four years, the collaboration had to 1) enrich the dataset to be fed into the tool, 2) investigate the technology to be implemented in the tool, 3) develop the tool, and 4) the historians should use all these things to conduct their research. Yet this did not work in practice. In the conflicts described above, delays in data, in computational research and in tool development rendered the promise that historians would use it for fundamental research unattainable. Furthermore, since funders preferred to fund innovations rather than continued work, it was difficult to do a follow-up project in which historians would use the tool developed in the preceding project, as exemplified in quote Q73. This time frame arguably stimulated the detachments of historians and computational researchers, as they anticipated that delays could ultimately lead to failure, which should be prevented at all costs.

Another external party shaping the field of action of the collaboration was arguably the cultural heritage institute as data provider. Data providers both enabled as well as confined practices by providing data in a certain shape. The power relation here was unintended, yet still present. Collaborations were confronted with incomplete datasets, data in incompatible formats, datasets with many mistakes, or datasets that still needed to be digitised (e.g., quotes Q65 and Q66). These complexities shaped what a collaboration could achieve in the time frame and tools were changed significantly to accommodate the available data. Here too, knowledge asymmetry played a role in the sense that researchers lacked insight in the

390 See also Franssen et al., “The Drawbacks of Project Funding for Epistemic Innovation.” 
quality and form of data until they received it. Furthermore, funding played a role as cultural heritage institutes joined collaborations as "partners" rather than "collaborators". Consequently, the digitisation of sources or the rectifying of data were regularly tasks for which a budget was not available. Even when collaborations were aware of the need to digitise additional material, they were not adequately prepared for incomplete data. The expectation of the transformed dataset was less an ambition than a necessity, and significantly altered the design and planning of collaborations.

\section{Trading Zones Resulting from Power Relations}

The interactions between the communities of collaboration instigators, historians and technologists, as well as with funders and data providers, thereby exemplified a range of different types of trading zones. The detachment by historians and computational researchers arguably led to disconnected trading zones by moving towards individual pursuits rather than mutual engagement. Insofar as this strategy enabled researchers to shape their own practices, these trading zones could be characterised as disconnected-symmetric-heterogeneous (boundary object) trading zones. That is, collaborators no longer actively engaged with one another to exchange, trade or push practices across disciplinary boundaries. The collaboration itself thereby functioned as a boundary object, with participants subscribing to the general purpose of a collaboration, while individually shaping goals according to their incentives.

In contrast, knowledge asymmetry led to asymmetric-homogeneous (subversive) trading zones, both connected or disconnected. That is, with or without engagement, historians saw their practices pushed and shaped by what computational experts provided. In these cases, two strategies emerged. First, in the case of connected subversive trading zones, participants aimed to develop know-how in order to decrease knowledge asymmetry. The aim was to develop a connectedsymmetric-heterogenous (interactional expertise) trading zone where the historical and computational communities could engage with one another through a broker who could coordinate in-between with adequate know-how of both sides. Second, in the case of disconnected subversive trading zones, collaboration instigators decided to work with software developers or IT personnel in a service role, rather than computational experts as equal partners. This led to a disconnectedasymmetric-heterogeneous (enforced) trading zone, without mutual sharing of practices and the ability to more simply demand certain services. Finally, being external to collaborations, funders and data providers shaped the practices of a collaboration without the ability for reverse shaping of funders and data providers. 
However, the lack of continuous negotiation allowed collaborations to recontextualise demands or datasets. Collaborations reimagined how to interpret the boundaries set by funders and data providers, thereby arguably shaping their own practices. During the collaboration, the grant requirements and datasets thereby constituted boundary objects as part of disconnected-symmetric-heterogeneous (boundary object) trading zones.

\section{Resistance}

The philosopher Michel Foucault argued that power relations lead to resistance. ${ }^{391}$ When a person sees their field of action being shaped by another party, they will respond. When this person sees the shaping as not in their own best interest, certain forms of resistance may occur. In the digital history collaborations that I have investigated, resistance was performed in the detachment of incentives. Historical research was detached and retracted to the community of historians, hardly bridging disciplinary boundaries anymore. Likewise, computational research was detached and retracted to the disciplinary communities of computational researchers. This detachment served as a risk aversion strategy, to sever dependencies that may lead to one's own research failing.

However, I also interpret this detachment as a strategy to protect disciplinary practices. For the historians, the important goal was to publish historical papers or a historical thesis, in order to advance their careers in the historical disciplinary culture. Likewise, for the computational researchers, the important goal was to publish papers that would help advance their careers in their computational disciplinary cultures. Detachment of incentives served to protect oneself from entering too far into another disciplinary culture, similar to the metaphor of the fly caught in the spider's web. Ultimately, the PhD candidate needed to write an individual and disciplinary thesis, not a collaborative interdisciplinary digital history thesis, as exemplified by quote Q9 and others.

In cases where the shaping by another was seen as advantageous to oneself, a scholar might instead choose to succumb. When the professor in history shaped the field of action of the $\mathrm{PhD}$ candidate in history, the response was not resistance. The response was instead enculturation, where the $\mathrm{PhD}$ candidate learned the practices of the historical discipline, their perceived own disciplinary community, through their supervisor. ${ }^{392}$ A question may be whether some

391 Foucault, "The Subject and Power."

392 Brown, Collins and Duguid, "Situated Cognition and the Culture of Learning." 
historians then choose to learn of other disciplinary practices, such as software development and computational research, in order to position themselves more strongly in digital history as a career opportunity (e.g., see quote Q69), or in order to decrease knowledge asymmetry. In the next and final chapter, I explore the dimension of changing practices and the extent to which historians indeed shift towards computational cultures. 